\title{
Moving Beyond "Special Needs"
}

\section{A Function-Based Framework for Emergency Management and Planning}

\author{
June Isaacson Kailes \\ Western University of Health Sciences \\ Alexandra Enders \\ University of Montana
}

\begin{abstract}
Disaster preparation and emergency response processes, procedures, and systems can be made more effective for people with disabilities, as well as for the population as a whole. An essential element of building appropriate levels of capacity, specific planning, and response success is to move beyond use of the "special needs" category, to better identify and address the diverse needs of those included under this label. This article provides disability demographics and describes special needs populations to lay the foundation for this change. It suggests the development of a more accurate and flexible planning and response framework based on essential, sometimes overlapping, functional needs: communication, medical needs, maintaining functional independence, supervision, and transportation (C-MIST). It also proposes new approaches to functional support, leadership, service delivery, and training.
\end{abstract}

The 2005 hurricane season in the United States reinforced the need to discontinue the use of all-inclusive labels such as special needs for disaster planning. Combining groups too broadly translates into imprecise planning and, as a result, emergency response failures. As the term is typically used, the special needs population makes up at least half of the U.S. population. The label special needs generally incorporates people whose functional needs include assistance with communication, medical needs, maintaining functional independence, supervision, and transportation (C-MIST). Not receiving C-MIST support when it is needed can have severe consequences for those who need it. As a result, to ensure that the needs of this large segment of the population receive necessary attention, it is vital that disaster preparation include a plan for operationalizing support for the population's needs.

The purpose of this article is to begin to identify the groups included in the population of special needs that require specific disaster planning above and beyond the average person. In addition, we explore a framework for disaster planning based upon identifying and addressing functional needs through the use of functional supports, leadership, service delivery, and training.

\section{Who Are People With "Special Needs"?}

Identifying the demographics of who is included in the term special needs will help planners better understand how to rec- ognize and meet their needs in an emergency. As it is widely used within disaster services and the emergency management field, the term special needs generally includes an extremely broad group of people, including people with disabilities, people with serious mental illness, minority groups, non-English speakers, children, and the elderly (Centers for Disease Control and Prevention [CDC], 2004). Other lists add single working parents, people without vehicles, people with special dietary needs (Federal Emergency Management Agency [FEMA], 2004), pregnant women, prisoners, people who are homeless, and others. While there appears to be little consensus on exactly who should be included in the special needs category, these groups represent a large and complex variety of concerns and challenges for disaster planning and response. Many of these groups have little in common beyond the fact that they are often left out of programs, services, and emergency planning (Kailes, 2000; National Council on Disability, 2005).

We conducted a demographic analysis to estimate the size of the special needs category. For consistency, we used the decennial Census 2000 data. The total of the most typical groups of special needs populations-people with disabilities, including people with serious mental illness; people who do not speak English or do not speak English well; children, ages 15 years and under; and people 65 years old and over-was almost 141 million people, $49.99 \%$ of the population. Table 1 shows the categories used, with age ranges for each. Everyone in the ages 15-years-and-under and ages 65-years-and-older categories was included. Because people with disabilities were 
TABLE 1

Emergency Management "Special Needs" Groups: Percentage of the U.S. Population

\begin{tabular}{|c|c|c|}
\hline Population category & Total & $\begin{array}{l}\text { \% U.S. total } \\
\text { population }\end{array}$ \\
\hline Children, age 15 and younger & $64,272,779$ & 22.84 \\
\hline Elderly, age 65 and older & $34,991,753$ & 12.43 \\
\hline $\begin{array}{l}\text { Speak English "not well," } \\
\text { ages } 18-64 \text { yrs }\end{array}$ & $5,703,904$ & 2.03 \\
\hline $\begin{array}{l}\text { Speak English "not at all," } \\
\text { ages } 18-64 \text { yrs }\end{array}$ & $2,575,154$ & 0.92 \\
\hline $\begin{array}{l}\text { Noninstitutionalized population } \\
\text { with a disability, ages } 16-64 \text { yrs }\end{array}$ & $33,153,211$ & 11.78 \\
\hline Total "special needs" population & $140,696,801$ & 49.99 \\
\hline
\end{tabular}

included in the 15-years-and-under and 65-years-and-older age categories, only the population 16 to 64 years was included in the disability category. This was necessary to avoid overcounting when an individual, such as a 70-year-old person with a disability, was in more than one category. Census data were not available for 16- and 17-year-olds who do not speak English or who do not speak English well, so we were only able to include people ages 18 to 64 in this category. Those ages 65 years and over would already be included in the elderly age category.

Populations not included in Table 1 include the entire institutionalized population. Including this segment $(4,059,039$ people; Census 2000 Summary File 1, Table PCT16) would bring the percentage of the population in the special needs category to $51.44 \%(144,755,840$ people out $281,421,906$ in the entire U.S. population reported in the Census 2000. People live in institutionalized group quarters because there is a perceived ongoing need for medical care and/or supervision. The residents of nursing homes, "hospitals/wards, hospices, and schools for the handicapped," correctional institutions, state prisons, and halfway houses have medical or supervision needs that will continue in an emergency. In addition, we did not include the almost quarter million individuals with disabilities who live in group homes, because in the Census 2000 they were counted in noninstitutionalized group quarters and already included in the Census 2000 tables for people with disabilities.

Minority groups are included in some lists of special needs populations (see Note 1). The United States continues to grow in racial and ethnic diversity. California, Hawaii, New Mexico, and Texas are "majority-minority" states, in which the majority of the population differs from the national majority population. Arizona, Georgia, Maryland, Mississippi, and New York have minority populations of $40 \%$ (U.S. Census Bureau,
2005). The Census 2000 reported more than 70 million minority individuals if the "White alone" population is subtracted from the total population. Because minorities were included in the age categories of 15 years and under and 65 years and older, only the population ages 16 to 64 years are counted here. Further adjusting for minority-group individuals who do not speak English and who are counted in the language category leaves 35 million to 40 million minority group individuals in the 16- to 64-year-old category.

Other groups with function-based needs that may not be captured in this analysis include people who are morbidly obese, pregnant women, people on kidney dialysis, and people living in zero-vehicle households (see Note 2).

- Obesity: People with morbid obesity can present a range of challenges in emergency management, from adequate rescue transportation modes to beds and chairs that will support them. The American Obesity Association (n.d.) reported that approximately 9 million adult Americans are morbidly obese, defined as having a Body Mass Index (BMI) of 40 or more. The prevalence of morbid obesity in 2003-2004 was $2.8 \%$ in men and $6.9 \%$ in women (Ogden et al., 2006).

- Pregnancy. The American Pregnancy Association (n.d.) reported that approximately 6 million pregnancies occur every year in the United States. A pregnant woman may have no needs beyond the need to avoid exposure to toxins, or she may be about to give birth and need medical assistance.

- Kidney dialysis. The United States Renal Data System at the National Institutes of Health (2003) reported that in 2001 there were 287,494 U.S. residents receiving kidney dialysis.

- Zero-vehicle households. The Census 2000 (Summary File 3, Table H44) reported that 10.8 million households out of about 110 million total occupied households did not have a vehicle. About 1.1 million of these households were in rural areas; the remainder were urban. (These are household numbers and cannot be directly added to the data on individuals.)

Although lack of a vehicle is generally considered a poverty issue related to lack of personal resources, some cities, such as New York and Washington, DC, typically have good public transportation systems and high rates of zero-vehicle households. In Manhattan, $77 \%$ of the households did not have a vehicle in 2000 , whereas $56 \%$ of the households in the five New York City boroughs combined had no vehicles. Loss of all or part of the transportation system can in and of itself be an emergency situation, but it is compounded by natural disasters, technological acts, or acts of terrorism, such as the 
terrorist attacks in New York City and Washington, DC, on September 11, 2001.

Given this demographic data, it is clear that special needs can cover much more than $50 \%$ of the nation's population, rendering the term meaningless. Some methods of calculating the totals approach $70 \%$ of the population, even when figuring in the overlap among categories. Continuing to use the term special needs does a disservice to every group included and greatly weakens the chances of planning for specific needs and providing an effective, comprehensive response.

The Nationwide Plan Review: Phase 2 Report (U.S. Department of Homeland Security, 2006) recommended developing a consistent definition of the term special needs. Unfortunately, there is no single term that can be substituted for special needs. Over the years, disability, cultural, and linguistic advocates have repeatedly pleaded to replace special needs with more precise, segmented, and discrete groupings, but they have been largely ignored. This is not simply a linguistic issue. Naming this functionally diverse group using a single term is equivalent to trying to describe more than half of the U.S. population. The large number of heterogeneous groups it represents is too large and too diverse for the use of any single designation.

\section{Who Are People With Disabilities?}

Disability is not a condition that affects the "special" or "unfortunate" few. Individuals with disabilities make up a sizable portion of the general population within the United States. According to the U.S. Census (Waldrop \& Stern, 2003), they represent $19.3 \%$ of the 257.2 million people ages 5 years and older in the civilian, noninstitutionalized population, or nearly one person in five. Disability is a common characteristic of and occurrence within the human experience. People with disabilities have the same range of personality traits, interests, and desires as everyone else. People with functional limitations are a part of the world's diversity (Kailes, 2002).

While people with disabilities will compose a major segment of any special needs population, as a group they are very heterogeneous. It is important to understand the range of function-based needs within the population. This approach leads to a common framework that can relate functional supports to functional needs, targeted at improving resource management in any type of incident.

Census 2000 asked disability questions related to sensory, physical, and mental functioning; the capacity for self-care; and difficulty going outside the home alone. Table 2 shows the numbers of people who reported within each of these categories, separated into age categories that correspond to Table 1: ages 5 to 15 years, ages 16 to 64 years, and ages 65 years and over. Individuals below age 16 years were not asked the question about going outside the home. There is overlap among these categories, because 1 individual may have reported more than one characteristic. While Census 2000 reported that there were about 49 million people with a disability, about 89 million separate conditions were reported (Waldrop \& Stern, 2003). However, because the Census 2000 category of "employment disability" is not relevant to the discussion of functional needs, the 21 million people ages 16 to 64 in this category were not included in Table 2 . This still leaves us with almost 68 million separate conditions reported. CDC's special needs category of people with serious mental illness is included functionally within the Census 2000 disability categories.

\section{Defining Functional Limitations Broadly}

Not all people who experience functional limitations consider themselves as having a disability. Some disability labels (e.g., spinal cord injury, amputation) are little more than diagnostic categories and say little about how the person actually functions. Generalizations based on particular types of disabilities have numerous exceptions. Two individuals with the same functional limitation may have very different abilities and needs. Like everyone, people with disabilities and functional limitations have different histories, resources, and attitudes (Kaplan, De Witt, \& Steyaert, 1992).

There are 67 places where disability is defined in federal laws and regulations (CESSI, 2003). Most of them are used to determine eligibility for programs such as Social Security Disability Insurance. Other definitions, such as the one in the

TABLE 2

Civilian, Noninstitutionalized Population by Age and Disability Type

\begin{tabular}{lcccccc}
\hline & \multicolumn{5}{c}{ Disability type } \\
\cline { 2 - 6 } Population age & Sensory & Physical & Mental & Self-Care & $\begin{array}{c}\text { Going outside } \\
\text { the home }{ }^{\mathbf{a}}\end{array}$ & Total \\
\hline $5-15$ yrs & 442,894 & 455,461 & $2,078,502$ & 419,018 & & $3,395,875$ \\
$16-64$ yrs & $4,123,902$ & $11,150,365$ & $6,764,439$ & $3,149,875$ & $11,414,508$ & $36,603,089$ \\
$65+$ yrs & $4,738,479$ & $9,545,680$ & $3,592,912$ & $3,183,840$ & $6,795,517$ & $27,856,428$ \\
Total & $9,305,275$ & $21,151,506$ & $12,435,853$ & $6,752,733$ & $18,210,025$ & $67,855,392$
\end{tabular}

Note. Data source: U.S. Census Bureau, Census 2000, Summary File 3, Table P41. All numbers are based on the civilian noninstitutionalized population. 
Americans with Disabilities Act (ADA), are used to establish civil rights and protections. Each definition offers specific eligibility criteria that are narrow and therefore inappropriate in the face of preparing for, responding to, and recovering from a disaster. These criteria may help determine access to, and distribution of, resources in the more long-term recovery stages. However, the closer to the time of the incident, the more need there is to focus on function-based needs and the functional supports required to address these needs.

In disaster management activities, it is important to think broadly about disability in terms of function and not in terms of an impairment or diagnosis. Traditional narrow definitions of disability are not appropriate. Disability is not limited to wheelchair users, people who are blind or deaf, or individuals covered by the ADA. Disability can include temporary limitations resulting from, but not limited to, surgery, accidents, and injuries (sprains, broken bones), pregnancy, and permanent conditions. Some disabilities result from the disaster itself and leave individuals more vulnerable because they have had no prior experience managing disability-related needs.

Individuals with disabilities include those with one or more activity limitations, such as a reduced capacity or inability to see, lift, walk, speak, hear, learn, understand, remember, manipulate or reach controls, and/or respond quickly. Some limitations are quite visible. For example, it is apparent when people use mobility devices, such as wheelchairs, canes, crutches, and walkers. Other limitations, such as heart disease; respiratory, emotional, or psychiatric conditions; arthritis; reduced stamina; significant allergies; asthma; multiple chemical sensitivities; and some visual, hearing, and cognitive disabilities may be less evident.

The concept that people either have a disability or do not have a disability perpetuates misperceptions about the nature of disability and functional limitations. Activity limitations exist along a continuum of severity and duration (partial to total, temporary to permanent) that affect almost everyone at some point in their lives.

Longer life expectancies and decreasing death rates from heart disease substantially prolong longevity and increase the numbers of people living with chronic and nonfatal but disabling conditions (Reis, Breslin, Iezzoni, \& Kirschner, 2004). As the population ages, people with disabilities and functional limitations rise in proportion to demographic changes. Medical and technological advances continue to keep more people with disabilities, chronic conditions, and functional limitations alive, healthy, and functioning independently. Planning for inclusiveness in emergency services is simply more efficient (National Council on Disability, 2000). Inclusive planning enables incident managers to have a common framework available for people with similar function-based needs. What they call themselves, how they have been labeled or diagnosed, or which programs they are eligible for is irrelevant.

Identifying impairment or diagnosis does not tell a person how to operationalize the need for functional support. There are a large number of impairment categories, diagnoses, and descriptions of individual differences. An impairment ("problem in body function or structure such as a significant deviation or loss" [World Health Organization, 2001, p. 10]) does not always lead to a functional limitation (Brandt \& Pope, 1997). For example, severe skin impairment may or may not cause functional limitation.

Using special needs language, especially when it focuses on an individual's impairment or diagnosis, does not provide a framework for relating individual characteristics, strengths, and capabilities to the individual's functional support needs. Adequately addressing functional support needs has a far greater impact on how well individuals survive than any specific diagnosis. Although everyone has functional needs, the consequences of not receiving C-MIST support for people who require it can be much more severe and much less forgiving. Some people do not have the same margin of resiliency, which is why this population is often labeled as "vulnerable."

By planning for people with functional needs, an operational set of predictable supports can be developed. A functional support framework provides for commonalities in planning among a large array of impairment types. This framework provides a way to operationalize support for functional needs and activity limitations that may be the same, even though the impairments may be very diverse. Asking "What is needed to maintain functional C-MIST?" avoids making inappropriate assumptions about what an individual does or does not need.

If planning does not embrace the value that everyone should have the chance to survive, few will (National Council on Disability, 2005). By adopting a broad, function-based approach, no one is left behind. Everyone involved, from planners to first responders, needs to address the broad spectrum of disability and functional limitation issues (Reis et al., 2004).

\section{People With Disabilities Are Part of Every Segment of the Population}

People with disabilities and activity limitations are very diverse and should not be sidelined or compartmentalized into a special needs box. Special implies difference and isolation. Among disability advocates, special is the label often used for segregated programs (Woodward, 1991). Programs and services continue to miss the mark when people are seen and served as people having special needs instead of people who are a part of every segment of the general population.

Individuals with disabilities and functional limitations live in the country and in cities, go to school, and work at home and in high-rise buildings. Most people with disabilities and functional limitations are integrated into and actively involved in society. If they live long enough, most people will age into disability. As time alters our bodies, activity and functional limitations are natural occurrences. There is an $80 \%$ chance that all people will experience a temporary or permanent disability at some point in their lives (Kailes, 2002). More than 
$40 \%$ of noninstitutionalized people ages 65 years and over have a disability (see Table 3 ).

However, it is important to recognize the largest number of individuals with disabilities-33 million people-are in the 16-to-64-years working-age population. Although the employment rate of people with disabilities is lower than that of people without disabilities, people with disabilities are both employees and employers. Emergency planning needs to include planning for people with disabilities in the workplace as well as for people in residential settings. Table 3 shows the prevalence of disability by age.

\section{Using a Function-Based Approach}

Accommodating this large group often translates into being better equipped to serve all people. Disasters and terrorism instantly increase the number of people with new disabilities and functional limitations.

In addition, emergencies can intensify an individual's vulnerabilities. In different environments, the level of support needed to reduce functional limitations changes. For example, an older person with moderate memory loss does quite well in his or her home but can become disoriented and confused due to transfer trauma in an unfamiliar environment. Loss of mobility equipment may render independent wheelchair users totally mobility dependent (Brandt \& Pope, 1997).

Effective planning and incident response, which includes people with a wide range of function-based needs, should be woven into the fabric and the culture of emergency management and disaster planning. As long as disability and other special needs groups are viewed as unique or special, the system's existing inefficiencies will continue. The following common framework incorporates function-based issues as routine elements in effective emergency planning and response.

\section{Function-Based Framework for Emergency Management and Planning}

This article proposes a flexible framework built on five essential function-based needs: communication, medical needs, maintaining functional independence, supervision, and transportation (C-MIST). The intent is to reduce negative consequences and improve readiness in all planning, preparedness, response, recovery, and mitigation activities. Addressing functional limitations includes both people who identify as having a disability and the larger number of people who do not identify as having a disability but who have a functional limitation in hearing, seeing, walking, learning, language, and/or understanding.

Federal and several state planning teams began the process for operationalizing this framework in 2006. This framework may need future refinement, but for now consider the following five areas of essential, and sometimes overlapping, functional needs and response, and how they could lead to specific action plans.
TABLE 3

Prevalence of Disability by Age

\begin{tabular}{lcc}
\hline Population age & Total & $\begin{array}{c}\text { \% U.S. age } \\
\text { category }\end{array}$ \\
\hline 5+ yrs & $257,167,527$ & 100.0 \\
With any disability & $49,746,248$ & 19.3 \\
5-15 yrs & $45,133,667$ & 100.0 \\
With any disability & $2,614,919$ & 5.8 \\
16-64 yrs & $178,687,234$ & 100.0 \\
With any disability & $33,153,211$ & 18.6 \\
65+ yrs & $33,346,626$ & 100.0 \\
With any disability & $13,978,118$ & 41.9 \\
\hline
\end{tabular}

Note. Data source: U.S. Census Bureau, Census 2000, Summary File 3: Table P42, civilian noninstitutionalized population 5 years and over.

Communication Needs. Most people who have limitations that interfere with the receipt of information and effective response to it are self-sufficient, but they need information provided in methods that they can understand and use. This is a very large and diverse population of those who will not hear, see, or understand in addition to those who cannot hear, see, or understand. They may not be able to hear verbal announcements, see directional signage to assistance services, or understand how to get food, water, and other assistance because of hearing, understanding, cognitive, or intellectual limitations. They include people who are ethnically diverse; who have limited or no ability to speak, read, or understand English; who have reduced or no ability to speak, see, and hear; and who have limitations in learning and understanding.

Effectively meeting communication needs can include posting content of oral announcements in a specified public area so that people who are deaf, hard of hearing, or out of hearing range can go there to get or read the announcements; designating a specific time of the day and place where foreign language and sign language interpreters will be available to communicate information; and employing trusted communitybased organizations that can effectively communicate with the communities they serve.

Medical Needs. People with visible disabilities tend to be automatically, but often mistakenly, placed in this category. A more specific function-oriented determination of medical needs must be incorporated into training on disaster management of medical needs. Medical needs can include managing unstable, terminal, or contagious health conditions that require observation and ongoing treatment; managing medications, intravenous (IV) therapy, tube feeding, and/or regular vital signs readings; administering dialysis, oxygen, and suction; managing wounds, catheters, or ostomies; and operating power-dependent equipment to sustain life.

Maintaining Functional Independence Needs. At-risk individuals who are identified early and screened, and whose 
functional independence needs are addressed within the first 48 hours can avoid costly deterioration of their health and functional mobility. Early disaster response intervention services offered through competent organizations that are familiar with functional needs allow people to maintain their health, mobility, and independence, as well as manage in mass shelters. Effectively meeting these needs prevents secondary conditions and institutionalization and reduces the use of scarce, expensive, and intensive emergency medical services.

Maintaining functional independence can include replacing essential medications for blood pressure management, seizures, diabetes, and psychiatric conditions; replacing lost or adaptive equipment (wheelchairs, walkers, scooters, canes, crutches) and essential consumable supplies (catheters, ostomy supplies, padding, dressings, sterile gloves); and assisting with orientation for those with visual limitations. It can include individuals who are not self-sufficient or who do not have or have lost adequate support from family or friends and need assistance with activities of daily living, such as bathing, feeding, going to the toilet, dressing, and grooming.

Supervision Needs. Support for individuals who do not have or have lost adequate support from family or friends must be determined on a case-by-case basis. For example, after an emergency some people with mental illness may be able to function well with healthy responses and coping skills, while others with serious and persistent mental illness may need a protected and supervised setting (U.S. Department of Health and Human Services, 1996).

People with supervision needs can include people who decompensate because of transfer trauma, trauma stressors that exceed their ability to cope, or lack of ability to function in a foreign environment; people with conditions such as dementia, intellectual disability, Alzheimer's, and psychiatric conditions such as depression, schizophrenia, and intense anxiety; people who function adequately in a familiar environment but become disoriented and lack the ability to function in an unfamiliar environment; prisoners; and unaccompanied children.

Transportation Needs. Emergency response requires mobility. Many people cannot drive due to disabilities, age, addictions, or legal restrictions (Littman, 2005). As noted in the demographic analysis, 10.8 million U.S. households do not have a vehicle. This includes people who are old, are poor, or need wheelchair-accessible transportation. Many nondrivers and people from zero-vehicle households can function independently once evacuated to safety.

Transportation is a well-established component of emergency response plans, and it merits detailed focus beyond the limited scope of this article. However, the lack of details regarding transportation-dependent people may be caused because "decision makers are unfamiliar with and insensitive to their needs" (Littman, 2005, p. 12). Emergency action plans need to routinely specify exactly who will do what and when to address the logistical and function-based needs of people with a wide range and different combinations of physical, economic, and social challenges.

\section{Improving Readiness Involves Leadership, Service Delivery, and Training}

Although government plays a major role in disaster planning and response, traditional government emergency agencies are not equipped to respond with the essential services needed by people with a variety of functional needs. Events of the 2005 U.S. hurricane season confirmed what has been recognized for decades: Traditional response and recovery systems are often not successful at meeting many human needs (National Council on Disability, 2005).

Typically, disaster preparedness and emergency response systems are designed for people for whom escape or rescue involves walking, running, driving, seeing, hearing, and quickly responding to directions. Emergency management systems need help with the very specific and sometimes complex needs of people with functional limitations. Well-intentioned emergency medical and public service personnel do not adequately address complex functional independence. They also do not address physical, communication, supervision, and transportation needs because they lack knowledge regarding available services, the values and goals of independent living and selfdetermination, human and civil rights laws and protections, and cultural and linguistic issues.

The Nationwide Plan Review: Phase 2 Report recommended that collaboration between governments and nongovernmental entities be strengthened at all levels. The authors of the report found that governments at all levels do not adequately involve civic organizations, faith-based organizations, special needs advocacy groups, the private sector, neighborhood associations, and educational institutions in planning processes. The report recommended that these organizations assist planners in developing and testing plans for public preparedness, direct assistance, and surge capacity.

Functional support coordinators (FSCs) could serve as "point people," vested with the responsibility, authority, and means to provide leadership, guidance, and coordination and resource management for emergency preparedness, disaster relief, and recovery operations. These positions should be within the emergency service agency at the senior executive level of government (federal, state, and local). The FSCs' qualifications should at a minimum include in-depth understanding and proven community-based experience. The FSC should have experience in implementing the values and goals of independent living and self-determination, implementing human and civil rights policies and procedures, and providing for people's complex function-based needs.

These FSCs would lead and coordinate activities that ensure that programs and services do the following:

- are accessible to, accommodate, and are inclusive of people with essential functional limitations; 
- employ the often overlooked abilities of some people with functional needs and activity limitations to provide specific types of human services as interpreters, ham radio operators, and shelter managers;

- document, disseminate, promote, and support the use of good practices;

- use community-based organizations (CBO) and nongovernmental organizations (NGO) and develop partnerships with experts who are closely connected to and trusted by the communities they serve;

- recruit, encourage, and provide sustained funding incentives that allow CBOs/NGOs to integrate disaster work into their mission;

- fund, orient, mobilize, and deploy teams of $\mathrm{CBOs} / \mathrm{NGOs}$ to coordinate disaster planning, preparedness, response, recovery, and mitigation services and integrate them with existing emergency systems in a way that is immediate, flexible, and collaborative;

- establish mutual aid agreements that integrate the strengths and skills of CBOs/NGOs into the emergency service plans and strategies of local government;

- integrate function-based issues into all emergency management courses so the subject is not considered "special";

- integrate and evaluate function-based scenarios, goals, and objectives in all drills, exercises, and after-action evaluations.

Functional support coordinators should be required to have the skills and the resources to build teams of qualified subject-matter experts who are knowledgeable in emergency management. These teams would also

- be present in shelters, temporary housing, and other disaster recovery centers;

- add intake screening questions that identify, triage, and track needs so people can maintain their functional independence by receiving appropriate "just in time" assistance, referrals, and long-term solutions;

- work side by side with and quickly orient shelter personnel and emergency managers to the essential functional needs of populations and to the resources available (National Organization on Disability, 2001);

- train shelter emergency personnel to distinguish between people who need only assistance in maintaining their health, medical stability, and mobility and those whose medical and supervision needs cannot be met by typical mass shelter services;
- train shelter emergency personnel to make "quick access fixes," such as installing temporary ramps and designating a specific time of the day and place where interpreters will be available to communicate information.

\section{Conclusion}

It is critically important to move beyond the category of special needs to a more effective, accurate, and flexible framework. A common framework based on essential functional needs is the crucial element for the following:

- building appropriate levels of capacity for disaster preparation, emergency response processes, procedures, and systems;

- adopting appropriate guidelines and protocols for resource management;

- strengthening service delivery and training;

- improving response successes;

- preventing secondary conditions and reducing institutionalization and the use of scarce, expensive, and intensive emergency medical services and the use of "downstream" services;

- allowing disaster services to integrate the value that everyone should have the chance to survive; and

- translating lessons documented into lessons learned and applied.

A special needs category does not work because it cannot be operationalized. It does not provide adequate guidance as to which operational tasks are required for an appropriate response. Continuing to use the term special needs does a disservice to every group included under its auspices (which represents over $50 \%$ of the nation's population) and translates into vague planning for specific needs, which results in response failures. "Future actions must be based on needs not doctrine" (Harrald, 2006).

\section{ABOUT THE AUTHORS}

JUNE ISAACSON KAILES is an associate director at the Center for Disability Issues in the Health Professions (CDIHP), Western University of Health Sciences, in Pomona, California. Inspired by the events of 9/11 and influenced by her past work in disaster preparedness, she authored Emergency Evacuation Preparedness: Taking Responsibility for Your Safety: A Guide for People with Disabilities and Other Activity Limitations. ALEXANDRA ENDERS is a senior research associate/policy analyst at the Research and Training Center on Disability in Rural Communities at the University of Montana. Her policy analysis focus is on infrastructure issues-transportation and telecommunications - that determine the availability, accessibility, and usability of the vehicles of modern participation. Address: June Isaacson Kailes, Center for Disability Issues in the Health Professions, 309 E. Second St., Pomona, CA 91766-1854 (e-mail: jik@ jik.com). 


\section{AUTHORS' NOTES}

1. This study was funded in part by CDIHP and in part by Grant H133B030501 from the U.S. Department of Education, National Institute on Disability and Rehabilitation Research, to the University of Montana Research and Training Center on Disability in Rural Communities.

2. This article expands on the ideas in Kailes (2005), which was supported in part by NIDRR Grant H133B000500-04B to the University of Kansas. The opinions expressed are those of the authors and do not necessarily represent those of sponsoring agencies.

3. We wish to acknowledge the assistance of Zack Brandt in analyzing the demographic distribution of people included in a wide variety of special needs categories and the disability community for constantly reminding us of the importance of the content of this article.

4. This article is dedicated to the many people who lost their independence or their lives because information transfer and the lessons learned and documented over the last 30 years are not yet applied.

\section{NOTES}

1. The only minority-group individuals included in Table 1 are those who are under 16 years old, over 65 years old, have a disability, or do not speak English.

2. The data for these groups were not included in Table 1, because either the source was not the 2000 Census or the numbers were for households and not individuals. Further, there was no way to correct for possible redundancy, e.g., a person with a disability who was morbidly obese.

\section{REFERENCES}

American Obesity Association. (n.d.). Morbid obesity (Fact sheet). Retrieved April 4, 2006, from http://www.obesity.org/subs/fastfacts/morbidobesity .shtml

American Pregnancy Association. (n.d.). Statistics. Retrieved April 4, 2006, from http://www.americanpregnancy.org/main/statistics.html

Brandt, E., \& Pope, A. (1997). Enabling America: Assessing rehabilitation science and engineering. Washington, DC: National Academy Press.

Centers for Disease Control and Prevention. (2004). Continuation guidanceBudget Year 5: Attachment H: Cross-cutting benchmarks and activities. Retrieved April 4, 2006, from http://www.bt.cdc.gov/planning/ continuationguidance/pdf/activities-attachh.pdf

CESSI. (2003). Federal statutory definitions of disability. Retrieved August 29, 2006, from http://www.icdr.us/documents/definitions.htm

Federal Emergency Management Agency. (2004). Are you ready? An in-depth guide to citizen preparedness (IS-22). Retrieved April 5, 2006, from http://www.fema.gov/areyouready/

Harrald, J. (2006). Hurricane Katrina: Recommendations for reform. Testimony for the Senate Homeland Security Government Affairs Committee, March 8, 2006. Retrieved September 26, 2006, from http://www.gwu .edu/ icdrm/publications/PDF/Harrald\%20HSGAC\%20testimony_rev .pdf
Kailes, J. (2000). Creating a disaster-resistant infrastructure for people at risk including people with disabilities. In A. B. Tufana \& M. Petal (Eds.), Trauma treatment professionals' training (pp. 41-63). Ankara, Turkey: Hacettepe University, School of Social Work.

Kailes, J. (2002). Who are people with disabilities and activity limitations? Playa del Rey, CA: Kailes-Publications. (http://www.jik.com/resource.html)

Kailes, J. I. (2005). Disaster services and "special needs"-Term of art or meaningless term? International Association of Emergency Managers Bulletin (Special Focus Issue: Emergency Preparedness for Individuals With Disabilities, Part 2, April, 2005).

Kaplan, D., De Witt, J., \& Steyaert, M. (1992). Laying the foundation: A report of the first year of The Blue Ribbon Panel on National Telecommunications Policy. Oakland, CA: World Institute on Disability.

Littman, T. (2005). Lessons from Katrina and Rita: What major disaster can teach transportation planners. Retrieved April 11, 2006, from http://www .vtpi.org/katrina.pdf

National Council on Disability. (2000). New paradigms for a new century: Rethinking civil rights enforcement. Retrieved April 11, 2006, from http:// www.ncd.gov/newsroom/publications/2000/paradigms.htm

National Council on Disability. (2005). Saving lives: Including people with disabilities in emergency planning. Retrieved April 5, 2006, from http:// www.ncd.gov/newsroom/publications/2005/saving_lives.htm

National Institutes of Health. (2003). United States renal data system 2003 annual data report. Bethesda, MD: National Institutes of Health, National Institute of Diabetes and Digestive and Kidney Diseases.

National Organization on Disability. (2001). People with disabilities unprepared for terrorist, other crises at home or at work, new poll finds. Retrieved April 11, 2006, from http://www.nod.org/index.cfm?fuseaction= page.viewPage \&page $I \bar{D}=1430 \&$ nodeID $=1 \&$ FeatureID $=507 \&$ redirected $=1 \&$ CFID $=1994474 \&$ CFTOKEN $=7199853$

Ogden, C. L., Carroll, M. D., Curtin, L. R., McDowell, M. A., Tabak, C. J., \& Flegal, K. M. (2006). Prevalence of overweight and obesity in the United States, 1999-2004. Journal of the American Medical Association, 295, 15491555.

Reis, J. P., Breslin, M. L., Iezzoni, L., \& Kirschner, K. (2004). It takes more than ramps to solve the crisis of healthcare for people with disabilities. Chicago: Rehabilitation Institute of Chicago. Also online at http://www.ric.org/ community/RIC_whitepaperfinal82704.pdf

U.S. Census Bureau. (2005). Texas becomes nation's newest "majority-minority" state (Press release). Retrieved April 3, 2006, from www.census.gov/PressRelease/www/releases/archives/population/005514.html

U.S. Department of Health and Human Services. (1996). Responding to the needs of people with serious and persistent mental illness in times of major disaster (Publication (SMA)96-3077). Washington, DC: Substance Abuse and Mental Health Services Administration.

U.S. Department of Homeland Security. (2006). Nationwide plan review: Phase 2 report. Retrieved September 1, 2006, from http://www.dhs.gov/ interweb/assetlibrary/Prep_NationwidePlanReview.pdf

Waldrop, J., \& Stern, S. (2003). Census brief: Disability status 2000. Washington, DC: U.S. Census Bureau. Also online at http://www.census.gov/ prod/2003pubs/c2kbr-17.pdf

Woodward, J. R. (1991, November). Time to get rid of "special"? The Disability Rag. Retrieved April 3, 2006, from http://www.jik.com/ilclang.html

World Health Organization. (2001). International classification of functioning, disability, and health. Geneva, Switzerland: Author. 